Article

\title{
The Effect of Carbohydrate Ingestion on Performance during a Simulated Soccer Match
}

\author{
Julia H. Goedecke ${ }^{1,2, *}$, Nicholas J. White ${ }^{1}$, Waheed Chicktay ${ }^{1}$, Hafsa Mahomed ${ }^{3}$, \\ Justin Durandt ${ }^{4}$ and Michael I. Lambert ${ }^{1}$
}

1 UCT/MRC Research Unit for Exercise Science and Sports Medicine, University of Cape Town, P.O. Box 115, Newlands, 7725, Cape Town 7700, South Africa;

E-Mails: nickwhitebio@gmail.com (N.J.W.); wchicktay@gmail.com (W.C.);

Mike.lambert@uct.ac.za (M.I.L.)

2 South African Medical Research Council, Parow, Cape Town 7505, South Africa

3 UCT/MRC Research Unit for Nutrition and Dietetics, Department of Human Biology, University of Cape Town, Cape Town 7700, South Africa; E-Mail: hafsamahomed@gmail.com

4 Discovery Health High Performance Centre, Sports Science Institute of South Africa, Newlands, Cape Town 7700, South Africa; E-Mail: JDurandt@ssisa.com

* Author to whom correspondence should be addressed; E-Mail: julia.goedecke@uct.ac.za; Tel.: +27-21-6504571; Fax: +27-21-6867530.

Received: 16 October 2013; in revised form: 1 December 2013 / Accepted: 4 December 2013 / Published: 16 December 2013

\begin{abstract}
Aim: This study investigated how performance was affected after soccer players, in a postprandial state, ingested a $7 \%$ carbohydrate $(\mathrm{CHO})$ solution compared to a placebo $(0 \% \mathrm{CHO})$ during a simulated soccer match. Methods: Using a double-blind placebo-controlled design, 22 trained male league soccer players (age: $24 \pm 7$ years, wt: $73.4 \pm 12.0 \mathrm{~kg}, \mathrm{VO}_{2} \max : 51.8 \pm 4.3 \mathrm{~mL} \mathrm{O} / \mathrm{kg} / \mathrm{min}$ ) completed two trials, separated by 7 days, during which they ingested, in random order, $700 \mathrm{~mL}$ of either a $7 \% \mathrm{CHO}$ or placebo drink during a simulated soccer match. Ratings of perceived exertion (RPE), agility, timed and run to fatigue were measured during the trials. Results: Change in agility times was not altered by $\mathrm{CHO} v s$. placebo ingestion $(0.57 \pm 1.48 v s .0 .66 \pm 1.00, p=0.81)$. Timed runs to fatigue were $381 \pm 267$ s vs. $294 \pm 159$ s for the $\mathrm{CHO}$ and placebo drinks, respectively ( $p=0.11$ ). Body mass modified the relationship between time to fatigue and drink ingestion ( $p=0.02$ for drink $\times$ body mass), such that lower body mass was associated with increased time to fatigue when the players ingested $\mathrm{CHO}$, but not placebo. RPE values for the final stage of the simulated soccer match were $8.5 \pm 1.7$ and $8.6 \pm 1.5$ for the
\end{abstract}


$\mathrm{CHO}$ and placebo drinks respectively $(p=0.87)$. Conclusions: The group data showed that the $7 \% \mathrm{CHO}$ solution (49 $\mathrm{g} \mathrm{CHO}$ ) did not significantly improve performance during a simulated soccer match in league soccer players who had normal pre-match nutrition. However, when adjusting for body mass, increasing CHO intake was associated with improved time to fatigue during the simulated soccer match.

Keywords: intermittent exercise; supplementation; sports drinks; football

\section{Introduction}

Soccer is defined as an intermittent sport characterised by periods of high-intensity play in addition to periods of sub-maximal effort over $\pm 90 \mathrm{~min}$. Players cover approximately 9-12 $\mathrm{km}$ per game, depending on their position and level of play [1,2]. The average intensity during a match is about $70 \%-75 \%$ of the $\mathrm{VO}_{2} \mathrm{max}$, with much of the energy demand coming from sprinting and other motions such as dribbling, heading, tackling and running backwards and sidewards [1,3]. The causes of fatigue during soccer are complex, and may involve various mechanisms acting centrally and peripherally [4]. However, one of the main mechanisms of fatigue during a soccer match is the depletion of liver and muscle glycogen $[5,6]$.

Many studies, which have examined the effect of carbohydrate (CHO) ingestion during simulated/real life soccer matches, have been comprehensively reviewed by Phillips et al. [7]. These studies have mostly used the Loughborough Intermittent Shuttle test (LIST), which elicits similar demands to a soccer match [8,9]. The players in most of these studies ingested $5 \mathrm{~mL} / \mathrm{kg}$ of a $6 \%-7 \%$ CHO solution prior to exercise, and $2 \mathrm{~mL} / \mathrm{kg}$ every $15 \mathrm{~min}$ during exercise [7]. In general, these studies have found that $\mathrm{CHO}$ ingestion before and during exercise reduces muscle glycogen utilization [10,11], maintains plasma glucose levels [12], improves running time to fatigue [13-15] and coordination [12,14] in the latter stages of the exercise trial. The effects on sprinting times were less consistent, with only a few studies showing improvements in sprinting performance [12,14]. More recently, the effects of CHO ingestion on simulated soccer performance have been undertaken in adolescents, the results being similar to those in adults, showing an overall improvement in time to fatigue $[16,17]$.

In their review, Phillips et al. [7] concluded "early research was almost unanimous in supporting the consumption of carbohydrate-electrolyte solutions during prolonged intermittent exercise for maintaining and/or improving exercise performance and capacity". However, the authors also concluded that many of the studies had methodological concerns that limited their applicability to actual team games. Notably, several studies have tested participants in a fasted state [12-14], or have not reported on the nutritional status of the participants $[16,17]$. This detracts from the interpretability of the data because in a real-life situation, players are not usually fasted before a match. Further, in a match situation, it is difficult to regulate the exact volume of fluid required by each player. Therefore our goal was to use a similar research design to what has been used previously [8], but to focus on the fact that the players started the trial in the same fed state as they would be before a match and each received the same volume of fluid throughout the simulated soccer match. 
Therefore, the aim of the study was to determine whether ingestion of $700 \mathrm{~mL}$ of a $7 \% \mathrm{CHO}$ solution, ingested immediately before and during the Loughborough intermittent shuttle test, would improve agility and running time to fatigue in league soccer players who had normal pre-match nutrition.

\section{Methods}

\subsection{Participants and Study Design}

Twenty-two male soccer players, currently involved in competitive local league soccer were recruited for the trial. After being informed of the nature of the study, participants gave their written consent to participate. The Human Research Ethics Committee of the Faculty of Health Sciences at the University of Cape Town approved the study.

In this randomized, double-blind, placebo-controlled trial, participants completed two trials, separated by 7 days. During the trials, participants ingested in random order either a commercially available $7 \% \mathrm{CHO}$ sports drink or a placebo beverage $(0 \% \mathrm{CHO})$ of similar taste and electrolyte concentration. All trials were held at approximately the same time of day, to negate any diurnal effect on results. The participants were instructed to prepare for the trial, from a nutrition and exercise perspective, as they would normally prepare for a soccer match, in an attempt to simulate pre-match conditions. However, they were asked to refrain from eating $2 \mathrm{~h}$ before the testing session to avoid any gastro-intestinal side effects.

During each trial, participants completed a previously validated simulated soccer match, followed by a run to fatigue (LIST) [8] and a modified Illinois agility test [18]. Body mass was measured pre- and post-exercise to estimate sweat losses. Participants recorded their ratings of perceived exertion [19] after every exercise bout, as well as following the run to fatigue. The design is summarised in Figure 1.

Figure 1. Schematic representation of the simulated soccer match adapted from the modified Illinois agility test [18] and the Loughborough Intermittent Shuttle Test (LIST) [8]. RPE, rating of perceived exertion; $\mathrm{R}$, rest; * ingested $50 \mathrm{~mL}$.

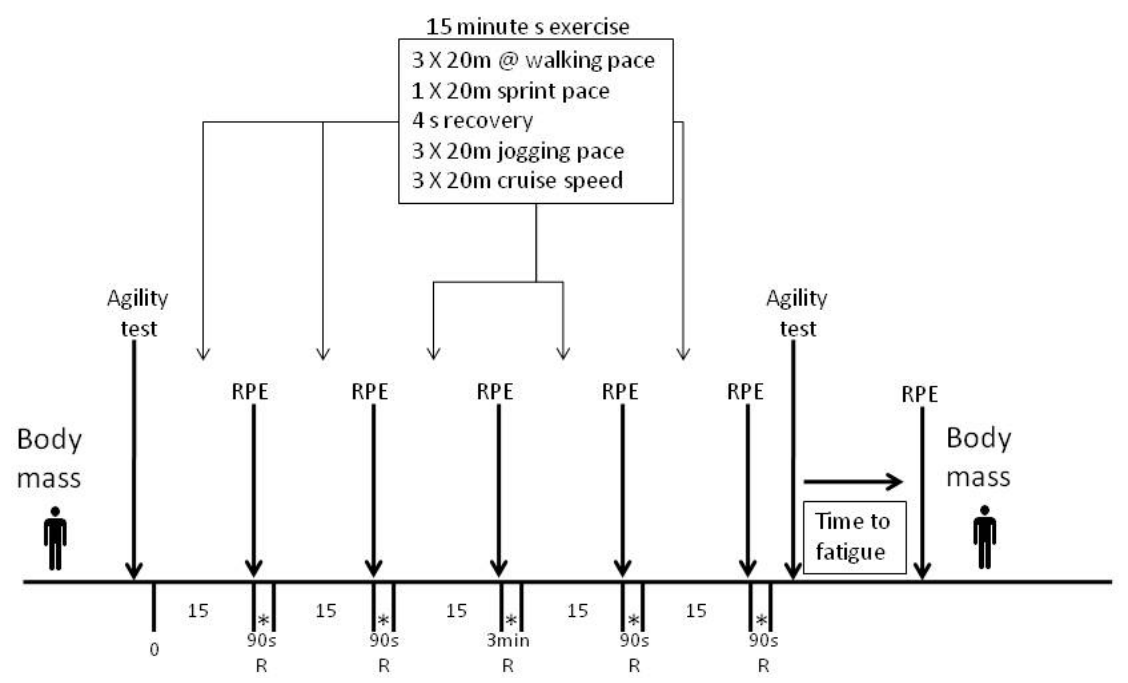




\subsection{Familiarisation}

Before the study, participants completed a familiarisation session during which body mass, height and skinfold thickness (bicep, triceps, sub scapular, suprailiac) were measured. Body fat percentage was estimated using the equations of Durnin and Womersley [20]. Participants then completed a multi-stage shuttle run to estimate their maximal oxygen uptake capacity $\left(\mathrm{VO}_{2} \max \right)$ [21]. The average $\mathrm{VO}_{2}$ max of the team was then used to calculate the speeds at which participants ran during the subsequent testing sessions in the LIST. To familiarise themselves with the testing protocol, each subject completed at least two 15-min bouts of the intermittent shuttle test.

\subsection{Dietary Intake}

Participants were instructed to eat as they would normally do in preparation for a soccer match and to replicate the same dietary strategy before each trial. Participants recorded their intake on the day leading up to each trial. The dietary records were analysed for total energy and macronutrient content using Foodfinder ${ }^{\circledR}$ Version 3 (National Nutritional Intervention Unit, MRC, Parow, Cape Town, South Africa, 2002).

\subsection{Exercise Trials}

On arrival at the laboratory, the pre-test body mass of the participants was measured. They then completed a $15 \mathrm{~min}$ standardised warm-up of stretching and jogging. Participants performed the pre-trial modified Illinois Agility test [18] to assess soccer-specific agility. During this test each participant dribbled a soccer ball through the cones set up according to a standard Illinois agility run. The participants were electronically timed during this test (Powertimer, Powertimer technology, Newtest Oy, Tyrnävä, Finland) to enhance accuracy. Each player did the test twice within a $15 \mathrm{~min}$ period, and the best score was recorded. The test was repeated if the participant lost control of the ball during the test.

Participants then completed the LIST [8], designed specifically to simulate soccer match conditions. The LIST was modified slightly to enable a team of players to be tested at the same time, and to allow time to complete the soccer-modified Illinois agility test prior to and following the LIST. The total time of the revised protocol, including rest breaks, was $90 \mathrm{~min}$. The test is divided into 2 parts. The first part consisted of 5 periods of $15 \mathrm{~min}$ of exercise, with each period separated by a $90 \mathrm{~s}$ break and a 3 min half-time break after the $3 \mathrm{rd}$ period. Each $15 \mathrm{~min}$ period consisted of the following pattern of repeated exercise, with the running speeds of $55 \%$ and $95 \%$ being calculated from the group predicted $\mathrm{VO}_{2}$ max using tables for predicted $\mathrm{VO}_{2}$ max values [21]:

$3 \times 20 \mathrm{~m}$ at a walking pace $(1.54 \mathrm{~m} / \mathrm{s} / 12.98 \mathrm{~s}$ for $20 \mathrm{~m})$

$1 \times 20 \mathrm{~m}$ sprint pace $(6.2 \mathrm{~m} / \mathrm{s} / 3.22 \mathrm{~s}$ for $20 \mathrm{~m})$

$4 \mathrm{~s}$ recovery

$3 \times 20 \mathrm{~m}$ at a jogging pace at $55 \%$ of the group-predicted $\mathrm{VO}_{2} \max (3.00 \mathrm{~m} / \mathrm{s})$

$3 \times 20 \mathrm{~m}$ at cruise speed, at $95 \%$ of the group-predicted $\mathrm{VO}_{2} \max (3.83 \mathrm{~m} / \mathrm{s})$ 
This pattern was repeated approximately 11 times in the 15 -min period. The running and walking speeds for each $20 \mathrm{~m}$ were dictated by an audio CD designed for this purpose. Participants then completed the soccer-modified Illinois agility test again. The change in performance in the agility test over the trial was thus determined.

Following the agility test, participants completed a timed run to fatigue, which consisted of $20 \mathrm{~m}$ runs at progressively increasing speeds. Fatigue was described as the point where the participant could not complete two consecutive shuttles.

The body mass of each participant was measured again, and the change in body mass over the trial was used as an indicator of sweat loss. The calculation considered the fluid ingested during the trial. Heart rate was recorded continuously throughout the trial using heart rate monitors (Suunto T6, Suunto, Amer Sports Corporation, Helsinki, Finland). The players' level of fatigue was measured using a visual analogue scale according to the Borg [19] following every 15-min exercise session, following the agility tests and following the completion of the run to fatigue.

\subsection{Drink Administration}

During each trial, participants ingested $700 \mathrm{~mL}$ of either a commercially available sucrose-based 7\% CHO sports drink (Energade, Tiger Consumer Brands Ltd., Bryanston, Johannesburg, South Africa) or an artificially flavoured placebo beverage $(0 \% \mathrm{CHO})$ of identical electrolyte concentration (sodium $41 \mathrm{mg} / 100 \mathrm{~mL}$, potassium $5 \mathrm{mg} / 100 \mathrm{~mL}$ ) and similar colour and taste.

Each participant ingested $250 \mathrm{~mL}$ of the randomly assigned drink, before the warm up and following the third 15-min exercise bout. In addition, $50 \mathrm{~mL}$ of the drink was ingested during the $90 \mathrm{~s}$ break separating each 15-min exercise bout. Consequently, participants ingested $49 \mathrm{~g}$ CHO during the CHO trial and no CHO during the placebo trial.

Participants completed a post-test drink survey to assess their perceptions of the drink (overall taste, after-taste, sweetness and level of stomach fullness or discomfort) on a visual analogue scale. The participants were also asked questions regarding the perceived performance benefits of the drinks, as well as possible side effects, and if they would use the drink during a soccer match in the future.

\subsection{Statistical Analyses}

Sample size was determined based on the findings of Welsh et al. [14] and Nicholas et al. [13]. Using a power of $80 \%$ and an $\alpha$ of 0.05 , with effects sizes for the differences between $\mathrm{CHO}$ and placebo trials of 0.69 and 0.59 , respectively, one would require a sample of 17-23 participants.

Data are presented as mean \pm standard deviation. Dependent $t$-tests were used to compare dietary intake before the two simulated soccer trials. Two-way ANOVA with repeated measures were used to measure differences over time between drinks with respect to heart rate, agility and rating of perceived exertion, with a Tukey HSD post-hoc analysis. Friedman ANOVA was used to analyse non-parametric data (subjective perception of drinks). ANOVA and ANCOVA, adjusting for body mass or body fat \%, were used to compare the change in heart rate, RPE, agility, and time to fatigue of the players when ingesting $\mathrm{CHO}$ or placebo. To determine whether differences in body mass (or body fat \%) of the players influenced the main outcome measures (time to fatigue and change in agility), multiple regression was used including drinks, body weight (or body fat \%) and their interaction (drink $\times$ body 
weight (or body fat \%)) as independent variables in the model. The Cohen's effect size was calculated to quantify the magnitude of difference between trials for the outcome measures of agility and time to fatigue. The following nomenclature of categorization was used: trivial $(\mathrm{ES} \leq 0.2)$, small $(\mathrm{ES}=0.2$ to 0.5 ), medium (ES $>0.5$ to 0.8 ) [22]. Statistical significance was accepted as $p<0.05$. Data were analysed using STATISTICA version 10 (Statsoft Inc., Tulsa, OK, USA) and STATA SE version 12.1 (StataCorp, College Station, TX, USA).

\section{Results}

The average age, body mass, height and body fat of the 22 soccer players was $24 \pm 7$ years, $73.4 \pm 12.0 \mathrm{~kg}, 171.4 \pm 4.7 \mathrm{~cm}$ and $16 \% \pm 5 \%$, respectively. Their mean $\mathrm{VO}_{2} \max$, estimated in a progressive shuttle run test, was $51.8 \pm 4.3 \mathrm{~mL} \mathrm{O}_{2} / \mathrm{kg} / \mathrm{min}$.

\subsection{Dietary Intake}

There was no significant difference in dietary intake in the day preceding the $\mathrm{CHO}$ and placebo trials, with the majority of energy intake being derived from CHO (Table 1).

Table 1. Average energy and macronutrient intake 1 day prior to the carbohydrate $(\mathrm{CHO})$ and placebo trials.

\begin{tabular}{cccc}
\hline & Placebo trial & CHO trial & $\boldsymbol{p}$ Value \\
\hline Energy $(\mathrm{kJ})$ & $6834 \pm 3723$ & $6335 \pm 3043$ & 0.621 \\
CHO $(\mathrm{g})$ & $209 \pm 130$ & $190 \pm 104$ & 0.533 \\
CHO $(\%)$ & $51.4 \pm 14.7$ & $51.3 \pm 14.0$ & 0.994 \\
Protein $(\mathrm{g})$ & $60 \pm 36$ & $53 \pm 20$ & 0.441 \\
Protein $(\%)$ & $17.6 \pm 14.9$ & $16.5 \pm 10.5$ & 0.770 \\
Fat $(\mathrm{g})$ & $53 \pm 27$ & $55 \pm 34$ & 0.856 \\
Fat $(\%)$ & $29.3 \pm 7.5$ & $31.0 \pm 10.3$ & 0.561 \\
\hline
\end{tabular}

Values are mean $\pm \mathrm{SD}$.

\subsection{Heart Rate and Rating of Perceived Exertion (RPE)}

Average and maximal heart rates recorded during the simulated soccer trial were not different between trials (Ave: $151 \pm 13$ vs. $150 \pm 15$ bpm, $p=0.813$; Max: $192 \pm 16$ vs. $188 \pm 13$ bpm, $p=0.268$, for placebo and CHO trials, respectively). RPE increased significantly following each 15 min stage of the simulated soccer match $(p<0.05)$, with a further increase following the run to fatigue $(p<0.05)$ (Figure 2), but there were no differences between $\mathrm{CHO}$ and placebo trials $(p=0.97)$. Adjusting for body mass or body fat $\%$ did not alter the findings. 
Figure 2. Changes in RPE during the simulated soccer match while ingesting the placebo (0\% CHO) and 7\% $\mathrm{CHO}$ solutions.

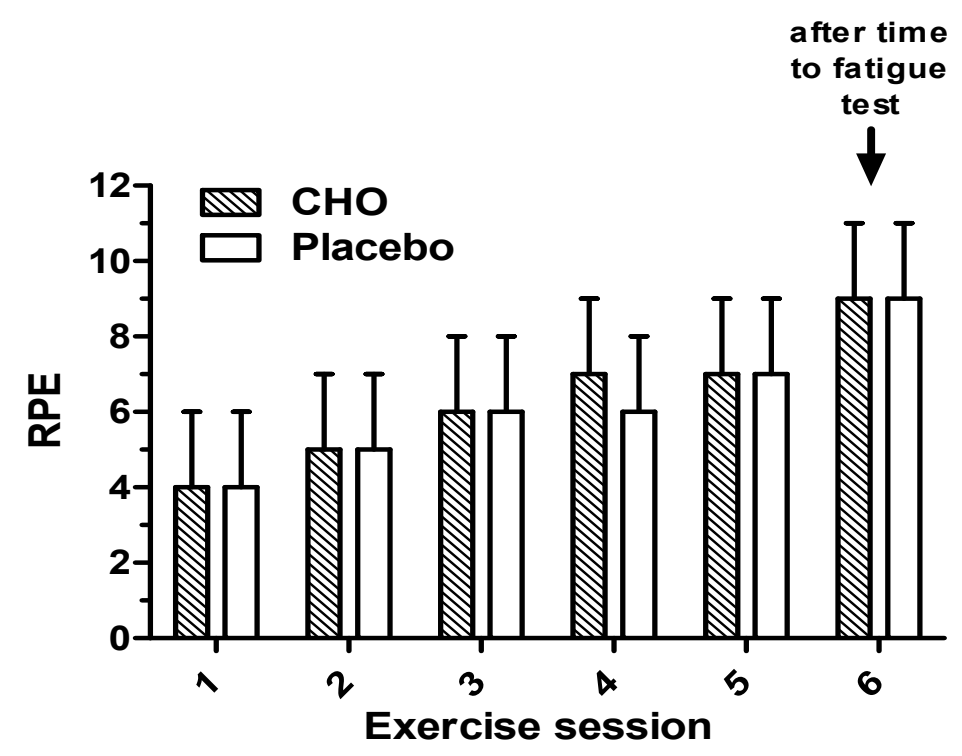

\subsection{Performance}

Agility and time to fatigue were not different between the $\mathrm{CHO}$ and placebo trials (Figure 3), even after adjusting for body mass and body fat \% (change in agility: $p=0.807$ and $p=0.776$; time to fatigue: $p=0.141$ and $p=0.182$, respectively). The effect size of the difference between the pre/post agility results ( $\mathrm{CHO}$ vs. placebo) was 0.01 (i.e., trivial), and the effect size of the difference between the time to fatigue ( $\mathrm{CHO} v$ s. placebo) was 0.39 (i.e., small). When exploring whether differences in body mass (or body fat \%) of the players influenced the performance outcomes, we found that body mass (but not body fat $\%, p=0.368$ ) modified the relationship between time to fatigue and drink ingestion ( $p=0.023$ for drink $\times$ body weight interaction), such that lower body weight was associated with increased time to fatigue when the players ingested $\mathrm{CHO}(r=-0.66,95 \% \mathrm{CI}$ : -0.85 to 0.33 , $p<0.001$ ), but not placebo ( $r=-0.2695 \% \mathrm{CI}$ : -0.62 to $0.18, p=0.235$ ) (Figure 4). No interaction effects between body mass or body fat \% and drink ingestion was found for change in agility ( $p=0.118$ and $p=0.462$, respectively).

Figure 3. Changes in agility (A) and the time to fatigue (B) during the simulated soccer match while drinking the placebo $(0 \% \mathrm{CHO})$ and $7 \% \mathrm{CHO}$ solutions.
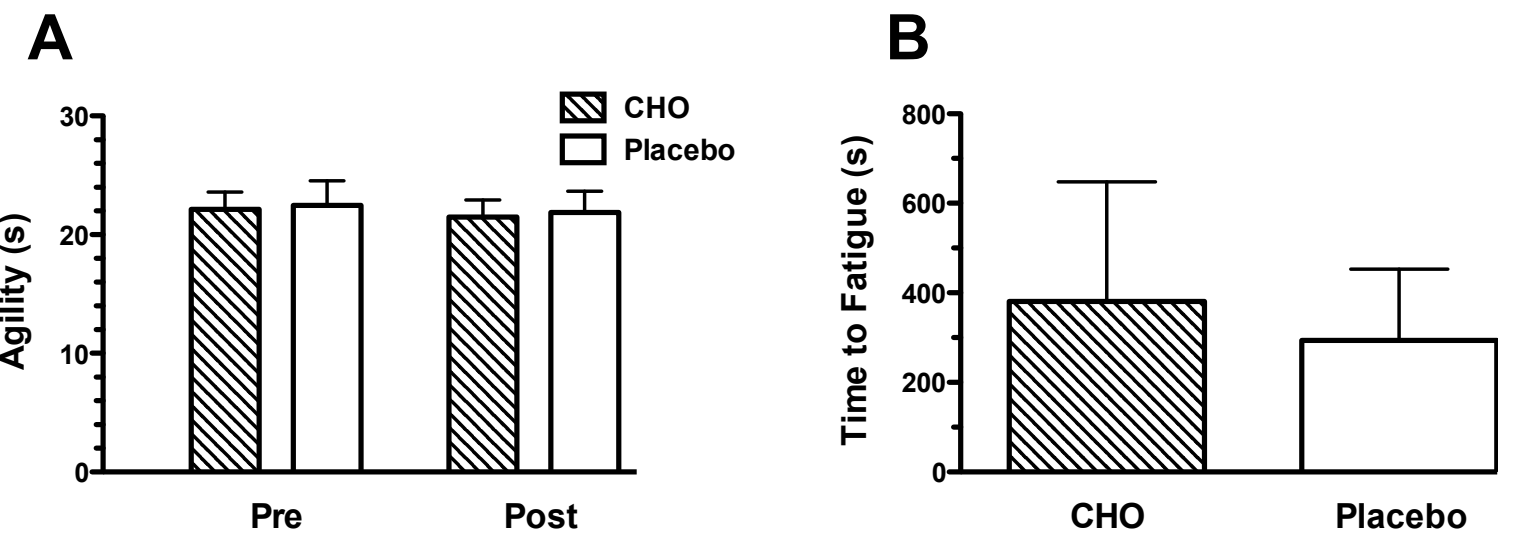
Figure 4. (A) The influence of body mass on time to fatigue during the simulated soccer match while ingesting the placebo $(0 \% \mathrm{CHO})$ or the $7 \% \mathrm{CHO}$ solutions $(p=0.023$ for drinks $\times$ body mass interaction). (B) The relationship between $\mathrm{CHO}$ ingestion $(\mathrm{g} / \mathrm{kg}$ body mass) and time to fatigue during the simulated soccer match.
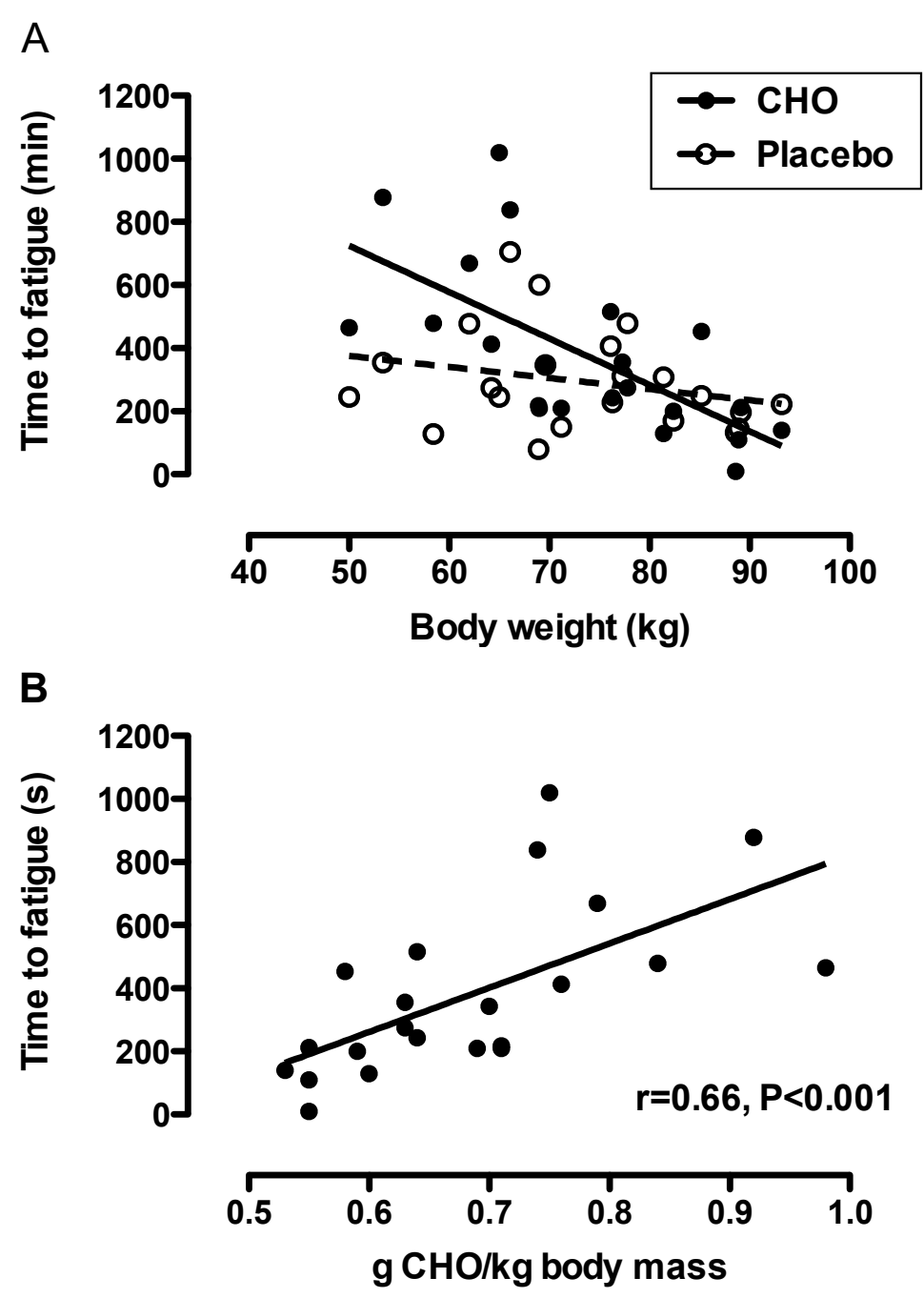

\subsection{Palatability of Drinks and Sweat Loss}

The participants' perception of taste, after-taste, sweetness and fullness between the CHO and placebo drinks were not different (Table 2). There was no difference in sweat loss between the two trials, with the average change in body mass over the trial being $0.90 \pm 0.43 v s .0 .88 \pm 0.37 \mathrm{~kg}$ ( $p=0.875)$ for the placebo and CHO trials, respectively.

Table 2. Palatability of $\mathrm{CHO}$ and placebo drinks.

\begin{tabular}{cccc}
\hline & Placebo trial & CHO trial & $\boldsymbol{p}$ Value \\
\hline Taste $(\mathrm{mm})$ & $6.8 \pm 2.4$ & $7.7 \pm 1.8$ & 0.11 \\
After-taste $(\mathrm{mm})$ & $2.8 \pm 2.4$ & $3.6 \pm 2.6$ & 0.26 \\
Sweetness $(\mathrm{mm})$ & $5.1 \pm 2.1$ & $5.6 \pm 1.9$ & 0.38 \\
Fullness $(\mathrm{mm})$ & $2.8 \pm 2.1$ & $3.5 \pm 2.6$ & 0.20 \\
\hline
\end{tabular}

Values are mean \pm SD. 


\section{Discussion}

Although many studies have examined the effects of $\mathrm{CHO}$ ingestion on simulated soccer performance (reviewed by [7]), most of these studies have tested participants who have started the trial in a fasted state. This research design has a low ecological validity, reducing the applicability of the results to real-life situations. Accordingly, we designed our study to mimic a real match situation as much as possible. The participants were encouraged to prepare as they would before a typical league match, including normal pre-match nutrition strategies. With this research design we showed that the ingestion of a 7\% $\mathrm{CHO}$ drink prior to, and during exercise, did not alter the group ratings of perceived exertion, heart rate response, agility, or running time to fatigue during a simulated soccer match. However, when examining the effects of body mass on performance, we found that the lighter players benefited more from $\mathrm{CHO}$ ingestion than the heavier players (Figure 4A). Increasing CHO intake (per kg body mass) was associated with increased time to fatigue during the simulated soccer match.

The improvement in time to fatigue in our study and others $[13,14]$ could be attributed to the effect of $\mathrm{CHO}$ ingestion on fuel metabolism during the $90 \mathrm{~min}$ simulated soccer match [4]. Indeed, studies have found that $\mathrm{CHO}$ ingestion before and during exercise reduces muscle glycogen utilization [10,11] and maintains plasma glucose levels [12]. The results of our study are somewhat surprising, as it has been shown previously that $\mathrm{CHO}$ ingestion improves $1 \mathrm{~h}$ exercise performance when $\mathrm{CHO}$ stores are sub-optimal, but not when the athletes start the trial in a $\mathrm{CHO}$ replete state [23]. In contrast, Krustrup et al. [6] showed that despite ingesting breakfast, as well as a meal $2 \mathrm{~h}$ prior to a friendly soccer match, muscle glycogen decreased significantly, with $47 \%$ of muscle fibres being completely or almost depleted of muscle glycogen after the game, Further, they showed that reduced muscle glycogen stores were associated with reduced performance in the latter stages of the soccer match, even though these friendly matches were performed at a lower intensity than those reported for elite competitive games [6]. More recently, Souglis et al. [24] showed that ingestion of a high CHO diet ( $8 \mathrm{~g} / \mathrm{kg}$ body mass) for 3 days prior to a soccer match increased the distance covered (from easy jogging to sprinting) compared to a low $\mathrm{CHO}$ diet ( $3 \mathrm{~g} / \mathrm{kg}$ body mass). The improvement in performance with $\mathrm{CHO}$ ingestion vs. placebo (when controlling for bodyweight) in our study could not be attributed to differences in CHO intake on the day leading up to the simulated soccer match, as their CHO intake was remarkably similar (209 vs. $190 \mathrm{~g}$ for the placebo and CHO trials respectively). However, the effects of CHO ingestion prior to and during the simulated soccer match may have been accentuated due to the players' relatively low $\mathrm{CHO}$ intake on the day prior to the trial ( $<3 \mathrm{~g} / \mathrm{kg}$ body weight).

During the trial, the participants drank a constant volume of CHO. However, this resulted in varying intake of $\mathrm{CHO} / \mathrm{kg}$ body mass, ranging from 0.53 to $0.98 \mathrm{~g} \mathrm{CHO} / \mathrm{kg}$ body mass. This affected the time to fatigue of the players, such that those who received more $\mathrm{CHO} / \mathrm{kg}$ had a greater improvement in performance than those who received less $\mathrm{CHO} / \mathrm{kg}$. The participants in our trial ingested $49 \mathrm{~g} \mathrm{CHO}$ during the $90 \mathrm{~min}$ simulated soccer trial $(28 \mathrm{~g} / \mathrm{h}$, including the $15 \mathrm{~min}$ warm-up period), which just falls outside the recommendation of 30-60 $\mathrm{g} \mathrm{CHO} / \mathrm{h}$ for activities of this nature [25]. However, based on our results, this is not sufficient to enhance performance, particularly in those participants with a larger body mass. Accordingly, when the mean performance results were compared between the $\mathrm{CHO}$ and placebo trials, there was no significant difference, masking the ergogenic potential of $\mathrm{CHO}$ ingestion 
(Figure 3). Irrespective of body mass, we observed large variability in response to CHO ingestion, which may reflect variability in phenotype for substrate oxidation [26].

Other studies that have previously shown an improvement in running time to fatigue $[10,13,14]$ and coordination $[12,14]$ in the latter stages of a simulated soccer match have administered $5 \mathrm{~mL} / \mathrm{kg}$ of a 6\%-7\% CHO solution prior to exercise, and $2 \mathrm{~mL} / \mathrm{kg}$ every $15 \mathrm{~min}$ during exercise, providing approximately $70-80 \mathrm{~g} \mathrm{CHO}$ during the $90 \mathrm{~min}$ trials, equivalent to approximately $0.9 \mathrm{~g} \mathrm{CHO} / \mathrm{kg}$ body mass [13-15]. Although the total fluid ingestion was also greater in this study than to our own $( \pm 1200 \mathrm{~mL}$ vs. $700 \mathrm{~mL}$, respectively), differences in performance could not be attributed to dehydration, as changes in body mass was similar between trials $(0.90 \mathrm{vs} .0 .88 \mathrm{~kg}$ for placebo and CHO trials, respectively).

$\mathrm{CHO}$ ingestion did not improve agility in our study, even after adjusting for differences in body size (Figure 3). Results relating to the effects of CHO ingestion on sprint and skill performance are less consistent than those for time to fatigue, with only a few studies showing improvements in sprint performance [12,14] and soccer skills [12,14,27]. However, this may be due to methodological issues rather than the influence of $\mathrm{CHO}$ ingestion [7].

This study is not without limitations. In trying to make the study conditions as representative of match conditions as possible we had to compromise on certain aspects in the research design. In particular the participants ingested a constant volume of $\mathrm{CHO}$ during the trial. However, we believe that this design may also be viewed as a strength, as we were able to demonstrate the body mass related relationship between $\mathrm{CHO}$ ingestion and performance during a simulated soccer match. Although we did not individually quantify the pre-match meal, we did quantify dietary intake during the day leading up to the research trials, which was not different between trials. However, it should be acknowledged that differences in the pre-exercise meal might have influenced performance. Other strengths of the study included the randomised, double blind, placebo controlled design. We used the LIST [8], which has been shown to elicit similar physiological and metabolic response compared to a match [8,28], and also included a soccer-specific agility test [18]. The palatability of the CHO and placebo drinks and other aspects of taste were not different, therefore it is unlikely that participants could distinguish between the two drinks. The 7\% $\mathrm{CHO}$ solution was a commercially available product, typically used by players in matches. The study had good statistical power and all participants were league soccer players and the design included all the players of two teams. However, these were league players of varying fitness $\left(\mathrm{VO}_{2}\right.$ max range from 42.4 to $58.2 \mathrm{~mL} / \mathrm{kg}$ body mass), and also body composition (body fat range from $10 \%$ to $21 \%$ body fat), which increased the variability of the results. Indeed, there was large variation in time to fatigue (Figure 4), which was influenced by body mass, but may also reflect the participants' individual responsiveness to $\mathrm{CHO}$. This is a plausible explanation because of the well-known phenotypic variation that exists, which manifests as predominantly $\mathrm{CHO}$ burners or fat burners [26].

\section{Conclusions}

In conclusion, the group data showed that ingestion of $700 \mathrm{~mL}$ of a $7 \% \mathrm{CHO}$ solution $(49 \mathrm{~g})$ did not significantly improve performance during a simulated soccer match in league soccer players who had normal pre-match nutrition. However, when adjusting for body mass, increasing CHO intake was 
associated with improved time to fatigue during the simulated soccer match. Based on these findings, the ingestion of a pre-match meal, as well as the provision of sufficient $\mathrm{CHO}$, based on body size, should be emphasised during a soccer match to ensure improved performance during the latter stages of a match.

\section{Acknowledgments}

This study was sponsored, in part, by Tiger Consumer Brands Ltd.

\section{Conflicts of interest}

The authors declare no conflicts of interest.

\section{References}

1. Bangsbo, J.; Mohr, M.; Krustrup, P. Physical and metabolic demands of training and match-play in the elite football player. J. Sports Sci. 2006, 24, 665-674.

2. Bangsbo, J. The physiology of soccer-with special reference to intense intermittent exercise. Acta Physiol. Scand. Suppl. 1994, 619, 1-155.

3. Mohr, M.; Krustrup, P.; Bangsbo, J. Match performance of high-standard soccer players with special reference to development of fatigue. J. Sports Sci. 2003, 21, 519-528.

4. Alghannam, A.F. Metabolic limitations of performance and fatigue in football. Asian J. Sports Med. 2012, 3, 65-73.

5. Rico-Sanz, J.; Zehnder, M.; Buchli, R.; Dambach, M.; Boutellier, U. Muscle glycogen degradation during simulation of a fatiguing soccer match in elite soccer players examined noninvasively by 13C-MRS. Med. Sci. Sports Exerc. 1999, 31, 1587-1593.

6. Krustrup, P.; Mohr, M.; Steensberg, A.; Bencke, J.; Kjaer, M.; Bangsbo, J. Muscle and blood metabolites during a soccer game. Med. Sci. Sports Exerc. 2006, 38, 1165-1174.

7. Phillips, S.M.; Sproule, J.; Turner, A.P. Carbohydrate ingestion during team games exercise: Current knowledge and areas for future investigation. Sports Med. 2011, 41, 559-585.

8. Nicholas, C.W.; Nuttall, F.E.; Williams, C. The loughborough intermittent shuttle test: A field test that simulates the activity pattern of soccer. J. Sports Sci. 2000, 18, 97-104.

9. Currell, K.; Jeukendrup, A.E. Validity, reliability and sensitivity of measures of sporting performance. Sports Med. 2008, 38, 297-316.

10. Nicholas, C.W.; Tsintzas, K.; Boobis, L.; Williams, C. Carbohydrate-electrolyte ingestion during intermittent high-intensity running. Med. Sci. Sports Exerc. 1999, 31, 1280-1286.

11. Leatt, P.B.; Jacobs, I. Effect of glucose polymer ingestion on glycogen depletion during a soccer match. Can. J. Sport Sci. 1989, 14, 112-116.

12. Ali, A.; Williams, C.; Nicholas, C.W.; Foskett, A. The influence of carbohydrate-electrolyte ingestion on soccer skill performance. Med. Sci. Sports Exerc. 2007, 39, 1969-1976.

13. Nicholas, C.W.; Williams, C.; Lakomy, H.K.A.; Phillips, G.; Nowitz, A. Influence of ingesting a carbohydrate-Electrolyte solution on endurance capacity during intermittent, high-intensity shuttle running. J. Sports Sci. 1995, 13, 283-290. 
14. Welsh, R.S.; Davis, J.M.; Burke, J.R.; Williams, H.G. Carbohydrates and physical/mental performance during intermittent exercise to fatigue. Med. Sci. Sports Exerc. 2002, 34, 723-731.

15. Davis, J.M.; Welsh, R.S.; Alerson, N.A. Effects of carbohydrate and chromium ingestion during intermittent high-intensity exercise to fatigue. Int. J. Sport Nutr. Exerc. Metab. 2000, 10, 476-485.

16. Phillips, S.M.; Turner, A.P.; Gray, S.; Sanderson, M.F.; Sproule, J. Ingesting a 6\% carbohydrate-electrolyte solution improves endurance capacity, but not sprint performance, during intermittent, high-intensity shuttle running in adolescent team games players aged 12-14 years. Eur. J. Appl. Physiol. 2010, 109, 811-821.

17. Phillips, S.M.; Turner, A.P.; Sanderson, M.F.; Sproule, J. Carbohydrate gel ingestion significantly improves the intermittent endurance capacity, but not sprint performance, of adolescent team games players during a simulated team games protocol. Eur. J. Appl. Physiol. 2011, 112, 1133-1141.

18. Roozen, N. Illinois agility test. NSCA's Perform. Train. J. 2004, 3, 5-6.

19. Borg, G. Ratings of perceived exertion and heart rates during short-term cycle exercise and their use in a new cycling strength test. Int. J. Sports Med. 1982, 3, 153-158.

20. Durnin, J.V.; Womersley, J. Body fat assessed from total body density and its estimation from skinfold thickness: Measurements on 481 men and women aged from 16 to 72 years. Br. J. Nutr. 1974, 32, 77-97.

21. Ramsbottom, R.; Brewer, J.; Williams, C. A progressive shuttle run test to estimate maximal oxygen uptake. Br. J. Sports Med. 1988, 22, 141-144.

22. Cohen, J. A power primer. Psychol. Bull. 1992, 112, 155-159.

23. Neufer, P.D.; Costill, D.L.; Flynn, M.G.; Kirwan, J.P.; Mitchell, J.B.; Houmard, J. Improvements in exercise performance: Effects of carbohydrate feedings and diet. J. Appl. Physiol. 1987, 62, 983-988.

24. Souglis, A.G.; Chryssanthopoulos, C.I.; Travlos, A.K.; Zorzou, A.E.; Gissis, I.T.; Papadopoulos, C.N.; Sotiropoulos, A.A. The effect of high vs. low carbohydrate diets on distances covered in soccer. J. Strength Cond. Res. 2013, 27, 2235-2247.

25. Burke, L.M.; Hawley, J.A.; Wong, S.H.S.; Jeukendrup, A.E. Carbohydrates for training and competition. J. Sports Sci. 2011, 29, S17-S27.

26. Goedecke, J.H.; St Clair Gibson, A.; Grobler, L.; Collins, M.; Noakes, T.D.; Lambert, E.V. Determinants of the variability in respiratory exchange ratio at rest and during exercise in trained athletes. Am. J. Physiol. Endocrinol. Metab. 2000, 279, E1325-E1334.

27. Currell, K.; Conway, S.; Jeukendrup, A.E. Carbohydrate ingestion improves performance of a new reliable test of soccer performance. Int. J. Sport Nutr. Exerc. Metab. 2009, 19, 34-46.

28. Magalhães, J.; Rebelo, A.; Oliveira, E.; Silva, J.R.; Marques, F.; Ascensão, A. Impact of loughborough intermittent shuttle test versus soccer match on physiological, biochemical and neuromuscular parameters. Eur. J. Appl. Physiol. 2009, 108, 39-48.

(C) 2013 by the authors; licensee MDPI, Basel, Switzerland. This article is an open access article distributed under the terms and conditions of the Creative Commons Attribution license (http://creativecommons.org/licenses/by/3.0/). 